\title{
Lymphadenectomy for Colorectal Cancer: Experience of the Brazzaville Teaching Hospital
}

\author{
Pierlesky Elion Ossibi ${ }^{*}$, Murielle Etiennette Julie Note Madzele1, Noé Hensnel Motoula Latou', \\ Didace Massamba Miabaou1, Prude Pertinie Avala1, Jile Florient Mimiesse-Monamou'2, \\ Arnaud Mongo-Onkouo², Rody Stéphane Ngami' ${ }^{2}$, Fabien Gael Mouamba ${ }^{3}$, Eliane Ndounga4, \\ Alexis Fortuné Bolenga Liboko4, Régis Franck Moyikoua5, Freznel Ngoma Mabonzo5, \\ Apendi Philestine Clausina Ahoui ${ }^{2}$, Gilbert Fabrice Otiobanda ${ }^{6}$, Blaise Irénée Atipo Ibara ${ }^{2}$
}

\author{
${ }^{1}$ Department of Digestive Surgery, Brazzaville Teaching Hospital, Brazzaville, Congo \\ ${ }^{2}$ Department of Gastroenterology, Brazzaville Teaching Hospital, Brazzaville, Congo \\ ${ }^{3}$ Anatomy and Pathological Cytology Department, Brazzaville Teaching Hospital, Brazzaville, Congo \\ ${ }^{4}$ Department of Oncology, Brazzaville Teaching Hospital, Brazzaville, Congo \\ ${ }^{5}$ Department of Radiology, Brazzaville Teaching Hospital, Brazzaville, Congo \\ ${ }^{6}$ Department of Intensive Care, Brazzaville Teaching Hospital, Brazzaville, Congo \\ Email: *oselion@yahoo.fr
}

How to cite this paper: Ossibi, P.E., Madzele, M.E.J.N., Latou, N.H.M., Miabaou, D.M., Avala, P.P., Mimiesse-Monamou, J.F., Mongo-Onkouo, A., Ngami, R.S., Mouamba, F.G., Ndounga, E., Liboko, A.F.B., Moyikoua, R.F., Mabonzo, F.N., Ahoui, A.P.C., Otiobanda, G.F. and Ibara, B.I.A. (2022) Lymphadenectomy for Colorectal Cancer: Experience of the Brazzaville Teaching Hospital. Surgical Science, 13, 79-90.

https://doi.org/10.4236/ss.2022.133011

Received: January 26, 2022

Accepted: March 5, 2022

Published: March 8, 2022

Copyright $\odot 2022$ by author(s) and Scientific Research Publishing Inc. This work is licensed under the Creative Commons Attribution International License (CC BY 4.0).

http://creativecommons.org/licenses/by/4.0/

\begin{abstract}
Introduction: Lymph node (LN) metastasis are important biomarkers in the resection of colorectal cancer translating into accurate disease staging. It is therefore obvious that lymph node dissection in the curative treatment of colorectal cancer is a prognostic factor that influences survival and guides management strategy. This study aims to evaluate lymph node dissection in colorectal cancers (CRC) managed at the Teaching Hospital, Brazzaville, Congo. Patients and Method: We carried out a descriptive prospective study during a period of 18 months from October 2020 to March 2021 involving patients who underwent curative treatment for colorectal cancer at the visceral surgery department of the Brazzaville Teaching Hospital. Results: Thirty (30) cases of CRC were recorded out of 738 hospitalizations in the visceral surgery departments, which constitute $4.06 \%$ of the in-patient activity of the department during the period under study. Mean age was 55.13 years and a male predominance was observed with a sex ratio of 1.14 . Colonic involvement was predominant in our series and was found in 22 of the patients. 25 patients underwent surgical resection while 5 patients could not undergo operative treatment. 17 out of the 25 patients underwent curative treatment, 6 were offered palliative care, whereas surgical abstention was decided in 2 patients. The average number of lymphadenectomies per patient was 16.43. Lymphadenectomy was greater than or equal to 12 in $88 \%$ of patients. Nine patients had vascular emboli whereas 10 patients had perineural invasion. The tumor was
\end{abstract}


staged as T3 in 15 patients; six patients had a negative lymph node and 11 patients had at least one lymph node invasion. Distant metastasis status could not be determined in 10 patients. Conclusion: Lymphadenectomy is a hallmark in the curative treatment of colorectal cancer as it allows for optimal staging. This represents a strong prognostic factor that defines adjuvant therapy and overall patient outcome.

\section{Keywords}

Lymphadenectomy, Surgery, Cancer, Colorectal

\section{Introduction}

Colorectal cancer (CRC) constitutes a major global public health concern as it represents the third most frequent cancer after lung and breast cancer [1].

Its incidence has increased over the past decade in developed countries. Its incidence is increasing in Africa, partly due to changes in dietary habits, lifestyle and improved diagnostic modalities and access to health care.

In addition to perioperative radiotherapy, chemotherapy or both, surgical resection with lymphadenectomy plays a key role in the management of operable colorectal cancers [2].

Lymphadenectomy is a major prognostic and therapeutic factor in the curative treatment of CRC [3]. Quality of lymphadenectomy is given by the number of lymph nodes assessed.

In clinical practice, the presence of lymph node metastasis determines the patients most likely to benefit from adjuvant chemotherapy [4] [5].

Although a minimum of 12 total lymph nodes dissected is highly recommended, debate exists as to the extent of lymphadenectomy. Some authors argue that extensive lymphadenectomy allows for better loco-regional control, eliminate undetectable lesions and thus improving disease free survival whereas others contend that extensive lymphadenectomy increases postoperative morbidity without improving disease-free survival as it is not the only gate way to metastatic disease [2].

The extent of lymphadenectomy, defined as the number of nodes removed, is crucial for accurate determination of $\mathrm{N}$ status in TNM staging. Lymph node dissection with sufficient resection appears to be mandatory.

The authors intend to assess lymphadenectomy in colorectal cancers for patients who underwent curative treatment at the Brazzaville Teaching Hospital.

\section{Patients and Method}

This is a prospective descriptive study spanning a period of 18 months from October 2020 to March 2021, involving patients who underwent lymphadenectomy for colorectal cancer at the Brazzaville Teaching Hospital. We excluded patients with peritoneal carcinomatosis, those who underwent palliative radiotherapy and/or 
chemotherapy, patients whose general condition could not allow for a curative treatment, cases with unresectable hepatic metastasis and patients with significant locoregional invasion, counter indicating a curative treatment.

The diagnosis of colorectal cancer was made on clinical presentation, biological, radiological, endoscopic features and confirmed on pathology findings.

Indications of treatment (chemotherapy, radiotherapy, surgery) was decided by interprofessional meetings.

The following variables were collated and analyzed: age, sex, anatomical location (right and left colon and rectum), the setting of surgery (scheduled intervention, urgent), the surgical approach (laparotomy), the prognostic factors (number of lymph nodes, degree of differentiation, presence of perineural sheathing or vascular emboli) and the tumor staging (pTNM).

Local ethics committee approval was obtained prior to patient selection based on in patient registry and surgical notes of the department of Digestive surgery department Brazzaville Teaching Hospital were retrospectively analyzed. Patients meeting the inclusion criteria were consecutively sampled. Data was collated on an Excel spreadsheet and analyzed using IBM SPSS 20 statistical analysis software.

\section{Results}

\subsection{Demographics}

Thirty (30) cases of CRC were collected out of 738 admissions in the visceral surgery departments accounting for $4.06 \%$ of the in-patient activity of the department.

This represents one case of CRC for every 24 admissions during the period under study.

In our study, the mean age was 55.13 years, ranging from 30 to 83 years

(Figure 1). Patients under 50 represent $26 \%$ of all colorectal cancer cases.

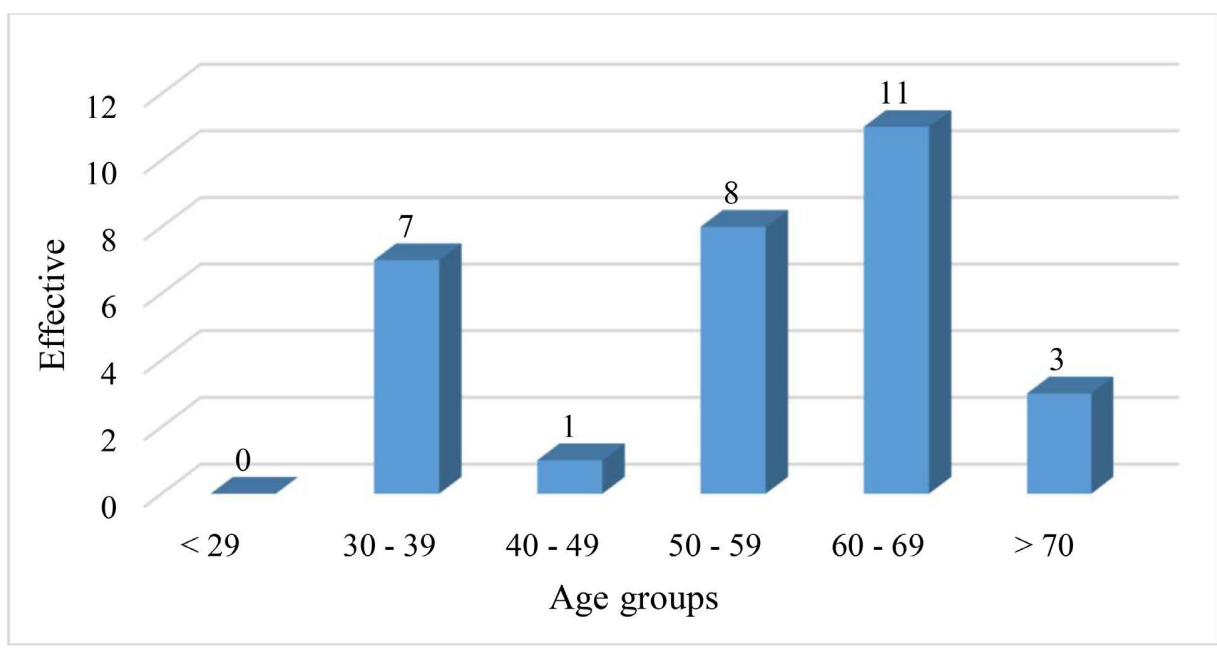

Figure 1. Patients' distribution according to age 16 men and 14 women were involved: a slight male predominance was observed with a sex ratio of 1.14 . 


\subsection{Clinical Setting}

The circumstances of discovery were mainly rectorrhagia in 20 patients $(66.66 \%)$, bowel obstruction syndrome in 7 patients (23.33\%), peritonitis in 2 patients $(6.66 \%)$ whereas an abdominal mass was found in 3 patients (10\%).

\subsection{Endoscopic Features}

Endoscopy remains the mainstay in the positive diagnosis of colorectal cancer. It was performed in 21 patients, and it allows to identify the lesion, specify its location, its macroscopic appearance and carry out multiple biopsies for pathological examination. Nine patients who presented in setting of acute abdominal pain could undergo endoscopic examination as emergent surgery had to be undertaken for acute bowel obstruction and peritonitis.

Pre-operative diagnosis of CRC was based on clinical presentation and imaging features (abdominopelvic CT).

Colonic localization was predominant in our series and was found in 22 of the patients. The distribution of colon cancer according to the site was as follows: right colon: 7 cases (31.81\%), transverse colon: 1 case (4.54\%), left colon: 4 cases (18.18\%), the sigmoid colon: 10 cases $(45.45 \%)$.

Regarding rectal cancer, the tumor was in 5 cases at the level of the lower third, 2 cases at the level of the middle third and 1 case at the level of the upper third.

The anatomopathological examination was carried out in all biopsies obtained from endoscopy.

A lieberkuhnian adenocarcinoma was found in all cases. Adenocarcinoma was well differentiated in 15 cases whereas it was moderately differentiated in 2 patients.

\subsection{Radiological Features}

$\mathrm{CT}$ was performed in all our patients as part of the locoregional assessment which showed a tumoral mass and/or parietal thickening (Figure 2). It also

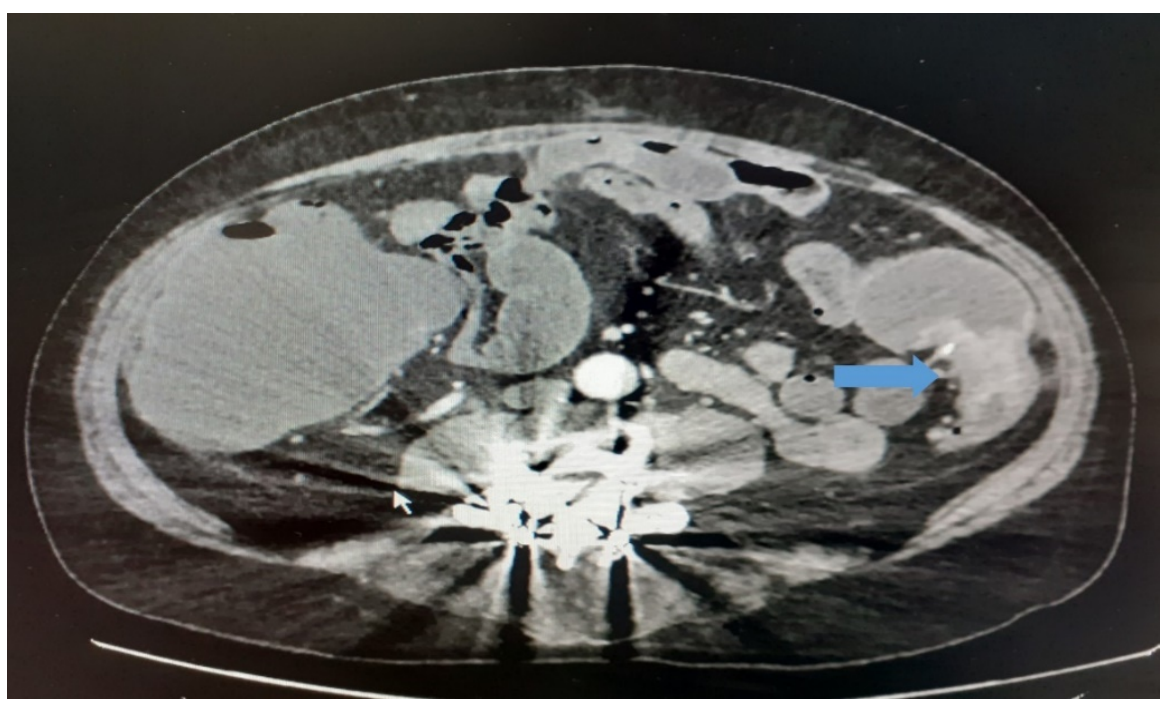

Figure 2. Image showing tumor thickening of the left colon. 
allows to detect metastases in the target organs (liver, lung, ovaries), as well as indirect signs of peritoneal carcinomatosis: ascites, nodule, and peritoneal thickening.

CT scan revealed hepatic metastases ( 7 cases); pulmonary ( 2 cases); ovarian (1 cases); and peritoneal carcinomatosis (4 cases)

\subsection{Surgical Procedure}

Among the 30 patients involved 25 patients underwent surgery, whereas 5 patients could not undergo surgery.

17 out of the 25 patients underwent curative surgery, 6 from palliative surgery (colostomy or internal diversion), while surgical abstention was decided in 2 patients.

11 of the 17 curative surgeries $(64.70 \%)$ were performed in an elective setting and $6(35.30 \%)$ were emergent resections (Figure 3).

Laparotomy was performed in all cases.

\subsection{Pathology Finding}

15 of the 17 patients who underwent curative surgery had satisfactory lymphadenectomy $(\mathrm{N} \geq 12)$ and in 2 patients the lymph node dissection was insufficient (one colon and one rectum) (Table 1).

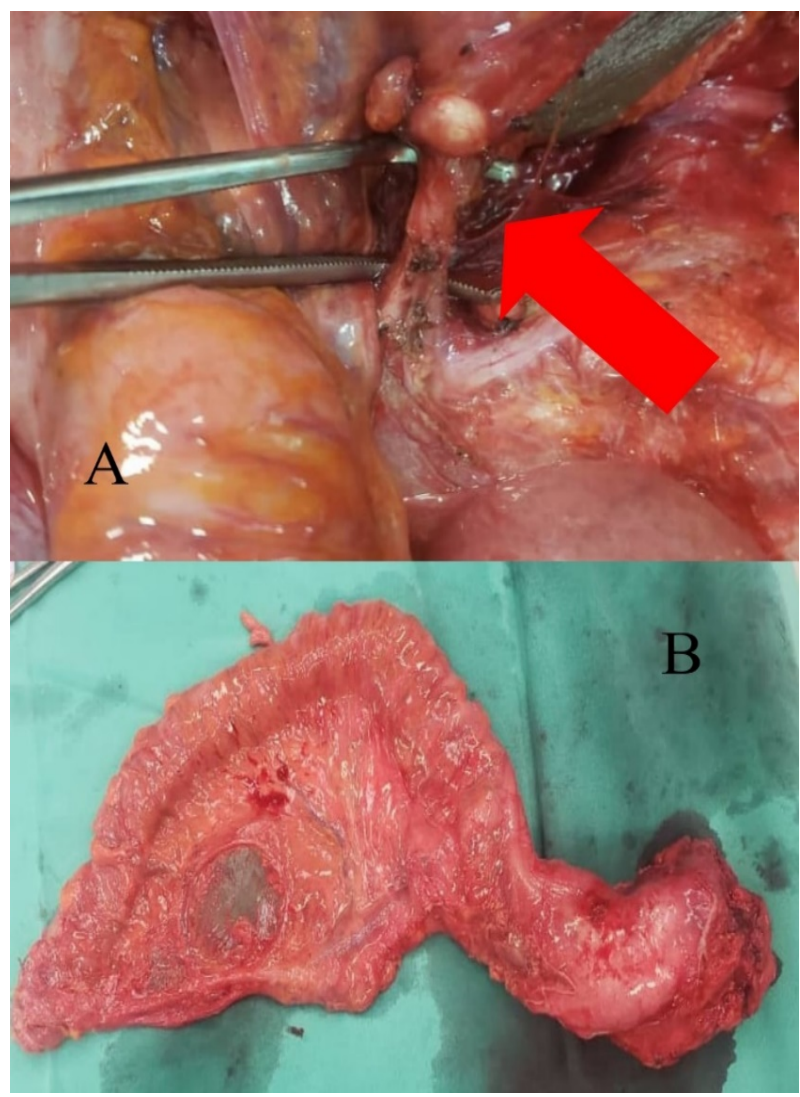

Figure 3. Image showing (A): dissection of the inferior mesenteric artery at its origin with the lymph nodes (Red Arrow); (B): surgical specimen of colo-proctectomy removing the left mesocolon and lymph nodes. 
Table 1. Summary of lymph node dissection.

\begin{tabular}{ccccc}
\hline \multirow{2}{*}{ Location } & Sex & Number & \multicolumn{2}{c}{ Lymph node dissection } \\
\cline { 3 - 5 } Colon & Male & 9 & 812 & $<12$ \\
& Female & 6 & 6 & 0 \\
\hline \multirow{2}{*}{ Rectum } & Male & 1 & 1 & 0 \\
& Female & 1 & 0 & 1 \\
\hline \multirow{2}{*}{ TOTAL } & & 17 & 15 & 2 \\
\hline
\end{tabular}

Nine (9) patients had vascular emboli and 10 patients had perineural invasion on surgical specimens. The resection margins were clean in all our specimens.

The pTNM classification based on the histological examination of the surgical specimen was as follows.

- $\mathrm{T}$ (tumour): $\mathrm{T} 3$ tumors were the most frequent in 15 patients, followed by T4 tumors (1 patient) and T2 (1 patient). There are no cases of T1 and T0.

- $\mathrm{N}$ (nodes): six patients had a negative lymph node status, four patients had an $\mathrm{N} 1$ status, i.e. $(1-3)$ lymph nodes invaded, and seven patients had an N2 status (more than 3 lymph nodes invaded).

- $\mathrm{M}$ (metastasis): distant metastasis could not be determined in 10 patients, 4 patients were staged as M0 and only three patients were classified as M1.

\section{Discussion}

The incidence of colorectal cancer is high in developed countries and data places it at the forefront of the mortality by cancer [6]. Rectal cancer accounts for $40 \%$ of colorectal cancers and $20 \%$ of digestive cancers.

Surgery is the only curative treatment for CRC, it entails tumoral resection as well total mesorectal excision of underlying vascular and lymphatic structures. Thus, lymphadenectomy remains an integral part of tumor excision and local control [7].

Lymph node invasion from the tumor occurs step by step, in principle, continuously, progressively and anatomically. However, there are cases of skip metastases, described as early as 1935 by Dukes, with varying incidences in literature (up to 10\%) [8] and retrograde invasion, which arise when the pedicular nodes are blocked by the tumor cells, via surrounding arches [9].

The aim of lymph node dissection is to obtain an accurate lymph node status in disease staging and to guide management [10].

Lymph node evaluation is fundamental in all colorectal cancer pathology staging systems, including the American Joint Committee on Cancer (AJCC) [11] [12], Dukes Modified [13], and Astler and Coller [14] staging systems. The most common system is the AJCC International Scale TNM system, which describes stages from I to IV based on depth of tumor invasion (T), status of positive local lymph nodes $(\mathrm{N})$ and distant metastases $(\mathrm{M})$. Its seventh edition has been re- 
vised to exclude cancers that cannot be evaluated for distant metastases [15] [16].

Briefly, a stage I tumor shows invasion (but not through) of the muscularis, stage II shows deeper tumor invasion, without spread into the LNs, stage III involves lymphatic spread and stage IV represents distant metastases [11] [12] [15] [16].

The United States Colorectal Cancer Registry (SEER) database shows that for each stage $\mathrm{T}$, the overall 5-year survival decreases with lymph node invasion.

\subsection{Concerning the Anatomopathological Examination of the Lymph Nodes}

Colorectal cancer is lymphophilic and can lead to lymph node metastases when the tumor crosses the muscularis mucosae [17]. Lymph node invasion is directly correlated with intramural extension of the tumor. Sitzler et al. [18] reported 5\%, 19\%, $65 \%$ and $78 \%$ lymph node invasion for $\mathrm{T} 1, \mathrm{~T} 2, \mathrm{~T} 3$ and $\mathrm{T} 4$ tumours, respectively.

When the number of lymph nodes found on the surgical specimen is low, additional methods such as dissolving the fat from the mesorectum using Bouin's solution are required to enable small lymph node detection [19] [20].

Scott et al. [21] examined colorectal resection specimens using conventional LN evaluation with and without fatty dissolution (xylene and alcohol). The mean number of nodes identified before and after fatty dissolution was 6.1 and 18.2 respectively.

Pathology examination of a colorectal resection specimen should include microscopic examination of all the lymph nodes of the mesocolon, the mesorectum and the mesenteric axis [22], which is particularly challenging as $50 \%$ to $70 \%$ of lymph nodes are less than $5 \mathrm{~mm}$ in diameter [20] [23]. Microscopic examination of several sections of the same lymph node increases the probability of diagnosing metastatic disease.

\subsection{Lymph Node Dissection and Correlation with Survival}

Previous studies have clearly demonstrated that patients with stage II disease and a poor LN dissection exhibited poor prognosis [11] [12] [24] [25]. Be it for colorectal cancer, or isolated cancer of the colon or rectum, the 5-year overall survival (OS) and disease-free survival (DFS) are significantly reduced in patients with low LN dissection.

Le Voyer et al. [26] showed that in patients with colon cancer, 5-year overall survival (OS) improves with increased NL resection.

Chen et al. [27], as well as Vather et al. [28] observed good survival rates with high LN dissection.

That notwithstanding, several studies did not report a similar correlation between survival and lymph node dissection in stage III disease [24] [29] [30] [31].

\subsection{Optimum Lymphadenectomy Required for Staging}

Although there is no consensus on the number of lymph nodes required on co- 
lorectal cancer resection specimen, a minimum of 12 to 17 lymph nodes is recommended to best determine lymph node status [32] [33], the risk of wrongly classifying a patient as N0 is less than $5 \%$ in case of a higher yield. In addition, the higher the number of nodes examined the more the chances of detecting a lymph node invasion [33] [34].

According to the latest recommendations from the International Union Against Cancer (UICC) [35], and the French Society for Digestive Surgery (SFCD) [36], the optimal number of NLs to be examined in CRCs is 12. [37] [38].

This figure would minimize under-staging and increase metastatic detection up to $92 \%$ [39].

The study by Nelson et al. [40] concluded that if 12 LNs are examined in a CRC resection specimen, lymph node metastasis is correctly evaluated in $90 \%$ of cases.

In colon cancers, if the total number of lymph nodes examined on the specimen is less than 6, adjuvant chemotherapy is recommended, because of the high risk of wrongly considering the patient as N0. No lower limit is currently accepted for rectal cancers. In a series by Charbit et al. [41] involving 200 patients who underwent complete mesorectal excision and rigorous pathological examination, the average number of lymph nodes examined was 19 , only $2 \%$ of patients had less than 5 lymph nodes examined and $10 \%$ of patients had less than 10 .

Bilimoria et al. [42] in a large cohort of patients monitored in hospitals in the United States, found that the CRC resection specimens included 12 nodes in more than $75 \%$ of the patients studied between the period from 1996-2005.

The results from the United Kingdom databases on colon cancer (2009) [43] showed that an average number of 15.1 lymph nodes were found in the excision pieces during the period 2006-2008.

Baxter et al. [44] studied 116,995 patients who underwent resection for CRC (without neoadjuvant chemotherapy). The median number of nodes examined was 9 , with only $37 \%$ of involving at least 12 nodes.

In our series, the average number of nodes examined was 16.43 with $88 \%$ of patients having a lymph node yield of at least 12 .

This variability in studies concerning the optimal number of LN is due to interobserver variability of this parameter and several factors that could influence lymph node dissection.

It is therefore vital to maximize lymph node yield in order to detect any metastases.

Lymph node dissection is a major prognostic and therapeutic factor [2] [3]. Hence quality of dissection (surgical and anatomopathological) should be assessed by the number of lymph nodes harvested and examined. Despite the small sample size, our results show that lymph node dissection was satisfactory in all our patients.

\section{Conclusions}

Lymphadenectomy remains a mainstay in the curative treatment for colorectal 
cancer as it allows for optimal staging. It also determines the postoperative management strategy and prognosis.

The results of our study demonstrate that most of our patients undergoing curative treatment for colorectal cancer at our department had adequate lymph node dissection.

Despite inter observer variability, the quality of lymph node dissection remains a key factor in management of colorectal with interprofessional surgical and pathological team involvement.

\section{Author Contributions}

All authors have read and approved the final version of this manuscript.

\section{Conflicts of Interest}

The authors declare no conflicts of interest regarding the publication of this paper.

\section{References}

[1] International Agency for Research on Cancer (2008) Cancer Incidence and Mortality Worldwide.

[2] Chen, Y.-J., Yeh, S.-T., Kao, P.-S., et al. (2020) A Reappraisal of Lymph Node Dissection in Colorectal Cancer during Primary Surgical Resection. World Journal of Surgical Oncology, 18, 97. https://doi.org/10.1186/s12957-020-01863-2

[3] Dillman, R.O., et al. (2009) Identification of 12 or More Lymph-Nodes in Resected Colon Cancer Specimens as an Indicator of Quality Performance. Cancer, 115, 1840-1848. https://doi.org/10.1002/cncr.24185

[4] Ong, M.L.H. and Schofield, J.B. (2016) Assessment of Lymph Node Involvement in Colorectal Cancer. World Journal Gastrointestinal Surgery, 8, 179-192. https://doi.org/10.4240/wjgs.v8.i3.179

[5] Gray, R., Barnwell, J., McConkey, C., Hills, R.K., Williams, N.S. and Kerr, D.J. (2007) Adjuvant Chemotherapy versus Observation in Patients with Colorectal Cancer: A Randomized Study. The Lancet, 370, 2020-2029. https://doi.org/10.1016/S0140-6736(07)61866-2

[6] Recht, A., Rutgers, E.J., Fentiman, I.S., Kurtz, J.M., Mansel, R.E. and Sloane, J.P. (1998) The Fourth EORTC DCIS Consensus Meeting (Château Marquette, Heemskerk, The Netherlands, 23-24 January 1998)—Conference Report. European Journal of Cancer, 34, 1664-1669. https://doi.org/10.1016/S0959-8049(98)00220-2

[7] Quirke, P. (2004) Training and Quality Assurance for Rectal Cancer: 20 Years of Data Is Enough. Lancet Oncology, 4, 695-702. https://doi.org/10.1016/S1470-2045(03)01248-8

[8] Gabriel, W.B., Dukes, C. and Bussey, H.J. (1935) Lymphatic Spread in Cancer of the Rectum. British Journal of Surgery, 23, 395-413. https://doi.org/10.1002/bjs.1800239017

[9] Harvey, H.D. and Auchincloss, H. (1968) Metastases to Lymph Nodes from Carcinomas That Were Arrested. Cancer, 21, 684-691.

https://doi.org/10.1002/1097-0142(196804)21:4<684::AID-CNCR2820210420>3.0.C $\underline{\mathrm{O} ; 2-\mathrm{R}}$ 
[10] Nagtegaal, I.D. and van Krieken, J. (2002) The Role of Pathologists in Quality Control of Diagnosis and Treatment of Rectal Cancer: An Overview. European Journal of Cancer, 38, 964-972. https://doi.org/10.1016/S0959-8049(02)00056-4

[11] Moertel, C.G., Fleming, T.R., Macdonald, J.S., Haller, D.G., Laurie, J.A., Goodman, P.J., Ungerleider, J.S., Emerson, W.A., Tormey, D.C., Glick, J.H., et al. (1990) Levamisole and Fluorouracil for Adjuvant Therapy of Resected Colon Carcinoma. New England Journal of Medicine, 322, 352-358.

https://doi.org/10.1056/NEJM199002083220602

[12] Swanson, R.S., Compton, C.C., Stewart, A.K. and Bland, K.I. (2003) The Prognosis of T3N0 Colon Cancer Is Dependent on the Number of Lymph Nodes Examined. Annals of Surgery Oncology, 10, 65-71. https://doi.org/10.1245/ASO.2003.03.058

[13] Mortenson, M.M., Khatri, V.P., Bennett, J.J. and Petrelli, N.J. (2007) Total Mesorectal Excision and Pelvic Node Dissection for Rectal Cancer: An Appraisal. Surgical Oncology Clinics of North America, 16, 177-197. https://doi.org/10.1016/j.soc.2006.10.007

[14] Astler, V.B. and Coller, F.A. (1954) The Prognostic Significance of Direct Extension of Carcinoma of the Colon and Rectum. Annals of Surgery, 139, 846-852.

https://doi.org/10.1097/00000658-195406000-00015

[15] Gunderson, L.L., Jessup, J.M., Sargent, D.J., Greene, F.L. and Stewart, A. (2010) Revised Tumor and Node Categorization for Rectal Cancer Based on Surveillance, Epidemiology, and End Results and Rectal Pooled Analysis Outcomes. Journal of Clinical Oncology, 28, 256-263. https://doi.org/10.1200/JCO.2009.23.9194

[16] Gunderson, L.L., Jessup, J.M., Sargent, D.J., Greene, F.L. and Stewart, A.K. (2010) Revised TN Categorization for Colon Cancer Based on National Survival Outcomes Data. Journal of Clinical Oncology, 28, 264-271. https://doi.org/10.1200/JCO.2009.24.0952

[17] Nascimbeni, R., Burgart, L.J., Nivatvongs, S. and Larson, D.R. (2002) Risk of Lymph Node Metastasis in T1 Carcinoma of the Colon and Rectum. Diseases of the Colon and Rectum, 45, 200-206. https://doi.org/10.1007/s10350-004-6147-7

[18] Sitzler, P., Seow-Choen, F., Ho, Y. and Leong, A. (1997) Lymph Node Involvement and Tumor Depth in Rectal Cancers: An Analysis of 805 Patients. Diseases of the Colon \& Rectum, 40, 1472-1476. https://doi.org/10.1007/BF02070714

[19] Farouk, A. and Rashad, R. (2017) Improved Detection of Lymph Nodes in Cases of Rectal Cancer Using Combined Methylene Blue Injection and Fat Clearance Compared with Fat Clearance Alone. The Egyptian Journal of Surgery, 36, 340-345. https://doi.org/10.4103/ejs.ejs_35_17

[20] Herrera, L. and Villarreal, J.R. (1992) Incidence of Metastases from Rectal Adenocarcinoma in Small Lymph Nodes Detected by a Clearing Technique. Diseases of the Colon \& Rectum, 35, 783-788. https://doi.org/10.1007/BF02050329

[21] Scott, K. and Grace, R. (1989) Detection of Lymph Node Metastases in Colorectal Carcinoma before and after Fat Clearance. British Journal of Surgery, 76, 1165-1167. https://doi.org/10.1002/bjs.1800761118

[22] Andreola, S., Leo, E., Belli, F., Bufalino, R., Tomasic, G., Lavarino, C., et al. (1996) Manual Dissection of Adenocarcinoma of the Lower Third of the Rectum Specimens for Detection of Lymph Node Metastases Smaller than $5 \mathrm{~mm}$. Cancer, 77, 607-612.

https://doi.org/10.1002/(SICI)1097-0142(19960215)77:4<607::AID-CNCR4>3.0.CO; 2-D

[23] Kotanagi, H., Fukuoka, T., Shibata, Y., Yoshioka, T., Aizawa, O., Saito, Y., et al. 
(1993) The Size of Regional Lymph Nodes Does Not Correlate with the Presence or Absence of Metastasis in Lymph Nodes in Rectal Cancer. Journal of Surgery Oncology, 54, 252-254. https://doi.org/10.1002/jso.2930540414

[24] Caplin, S., Cerottini, J.P., Bosman, F.T., Constanda, M.T. and Givel, J.C. (1998) For Patients with Dukes' B (TNM Stage II) Colorectal Carcinoma, Examination of Six or Fewer Lymph Nodes Is Related to Poor Prognosis. Cancer, 83, 666-672. https://doi.org/10.1002/(SICI)1097-0142(19980815)83:4<666::AID-CNCR6>3.0.CO; $\underline{2-\mathrm{I}}$

[25] Choi, H.K., Law, W.L. and Poon, J.T. (2010) The Optimal Number of Lymph-Nodes Examined in Stage II Colorectal Cancer and Its Impact of on Outcomes. BMC Cancer, 10, Article No. 267. https://doi.org/10.1186/1471-2407-10-267

[26] Le Voyer, T.E., Sigurdson, E.R., Hanlon, A.L., Mayer, R.J., Macdonald, J.S., Catalano, P.J. and Haller, D.G. (2003) Colon Cancer Survival Is Associated with Increasing Number of Lymph Nodes Analyzed: A Secondary Survey of Intergroup Trial INT-0089. Journal of Clinical Oncology, 21, 2912-2919. https://doi.org/10.1200/JCO.2003.05.062

[27] Chen, S.L. and Bilchik, A.J. (2006) More Extensive Nodal Dissection Improves Survival for Stages I to III of Colon Cancer: A Population-Based Study. Annals of Surgery, 244, 602-610.

[28] Vather, R., Sammour, T., Zargar-Shoshtari, K., Metcalf, P., Connolly, A. and Hill, A. (2009) Lymph Node Examination as a Predictor of Long-Term Outcome in Dukes B Colon Cancer. International of Journal Colorectal Disease, 24, 283-288. https://doi.org/10.1007/s00384-008-0540-y

[29] Tepper, J.E., O’Connell, M.J., Niedzwiecki, D., Hollis, D., Compton, C., Benson, A.B., Cummings, B., Gunderson, L., Macdonald, J.S. and Mayer, R.J. (2001) Impact of Number of Nodes Retrieved on Outcome in Patients with Rectal Cancer. Journal Clinical of Oncology, 19, 157-163. https://doi.org/10.1200/JCO.2001.19.1.157

[30] Prandi, M., Lionetto, R., Bini, A., Francioni, G., Accarpio, G., Anfossi, A., Ballario, E., Becchi, G., Bonilauri, S., Carobbi, A., Cavaliere, P., Garcea, D., Giuliani, L., Morziani, E., Mosca, F., Mussa, A., Pasqualini, M., Poddie, D., Tonetti, F., Zardo, L. and Rosso, R. (2002) Prognostic Evaluation of Stage B Colon Cancer Patients Is Improved by an Adequate Lymphadenectomy: Results of a Secondary Analysis of a Large Scale Adjuvant Trial. Annals of Surgery, 235, 458-463.

https://doi.org/10.1097/00000658-200204000-00002

[31] Sarli, L., Bader, G., Iusco, D., Salvemini, C., Mauro, D.D., Mazzeo, A., Regina, G. and Roncoroni, L. (2005) Number of Lymph Nodes Examined and Prognosis of TNM Stage II Colorectal Cancer. European Journal of Cancer, 41, 272-279. https://doi.org/10.1016/j.ejca.2004.10.010

[32] Chan, J.K., Kapp, D.S., Cheung, M.K., Osann, K., Shin, J.Y., Cohn, D. and Seid, P.L. (2007) The Impact of the Absolute Number and Ratio of Positive Lymph Nodes on Survival of Endometrioid Uterine Cancer Patients. British Journal of Cancer, 97, 605-611. https://doi.org/10.1038/sj.bjc.6603898

[33] Goldstein, N., Sanford, W., Coffey, M. and Layfield, L. (1996) Lymph Node Recovery from Colorectal Resection Specimens Removed for Adenocarcinoma. Trends over Time and Recommendation for a Minimum Number of Lymph Nodes to Be Recovered. American Journal of Clinical Pathology, 106, 209-216.

https://doi.org/10.1093/ajcp/106.2.209

[34] Compton, C., Fielding, L., Burgart, L., et al. (2000) Prognostic Factors in Colorectal Cancer: College of American Pathologist Consensus Statement 1999. Archives of Pa- 
thology and Laboratory Medicine, 124, 979-994. https://doi.org/10.5858/2000-124-0979-PFICC

[35] Sobin, L.H. and Wittekind, C.H. (2002) Digestive System Tumor in International Union against Cancer (UICC): TNM Classification of Malignant Tumors. 5th Edition, John Wiley and Sons, New York. https://doi.org/10.1002/0471463752

[36] Lasser, K.S. (2009) Digestive Oncology: Surgical Practices. Journal de Chirurgie, 146, S11-S80. https://doi.org/10.1016/S0021-7697(09)72398-1

[37] Canessa, C.E., Badia, F., Fierro, S., Fiol, V. and Hayek, G. (2001) Anatomic Study of the Lymph Nodes of the Mesorectum. Diseases of the Colon \& Rectum, 44, 1333-1336. https://doi.org/10.1007/BF02234794

[38] Topor, B., Acland, R., Kolodko, V. and Galandiuk, S. (2003) Mesorectal Lymph Nodes: Their Location and Distribution within the Mesorectum. Diseases of the Colon \& Rectum, 46, 779-785. https://doi.org/10.1007/s10350-004-6656-4

[39] Hermanek, H.P., et al (1994) What's New in TNM? Pathology Research Practice, 190, 97-102. https://doi.org/10.1016/S0344-0338(11)80505-4

[40] Nelson, H., Petrelli, N., Carlin, A., Couture, J., Fleshman, J., Guillem, J., Miedema, B., Ota, D. and Sargent, D. (2001) Guidelines 2000 for Colon and Rectal Cancer Surgery. Journal of National Cancer Institute, 93, 583-596. https://doi.org/10.1093/jnci/93.8.583

[41] Bader, L.S.G., et al. (2005) Number of Lymph Nodes Examined and Prognosis of TNM Stage II Colorectal Cancer. European Journal of Cancer, 41, 272-279. https://doi.org/10.1016/j.ejca.2004.10.010

[42] Bilimoria, K.Y., Stewart, A.K., Edge, S.B. and Ko, C.Y. (2008) Lymph Node Examination Rate, Survival Rate, and Quality of Care in Colon Cancer. Journal of the American Medical Association, 299, 896. https://doi.org/10.1001/jama.299.8.896-a

[43] McDonald, J.R., Renehan, A.G., O’Dwyer, S.T. and Haboubi, N.Y. (2012) Lymph Node Harvest in Colon and Rectal Cancer: Current Considerations. World Journal of Gastrointestinal Surgical, 4, 9-19. https://doi.org/10.4240/wjgs.v4.i1.9

[44] Baxter, N.N., Virnig, D.J., Rothenberger, D.A., Morris, A.M., Jessurun, J. and Virnig, B.A. (2005) Lymph Node Evaluation in Colorectal Cancer Patients: A Population-Based Study. Journal of National Cancer Institute, 97, 219-225.

https://doi.org/10.1093/jnci/dji020 